\title{
Proposal for an Ecological Research Center for the Recovery and Revaluation of Biodiversity in the Town of Quichas-Lima, Peru
}

\author{
Doris Esenarro, Ivana Escate, Leslie Anco, Carla Tassara, and Ciro Rodriguez
}

\begin{abstract}
To improve the quality of life of the inhabitants of the town of Quichas and promote their sustainable development, we propose an Ecological Research Center. This center allows the restoration and revaluation of biodiversity in the study area. During the exploratory research process, data was collected through observations, interviews and surveys; the areas of direct and indirect influence were delimited, tourist attractions, infrastructure deficiencies and the environmental and ecological situation of the area were identified. As a result of the information analysis, a proposal for sustainable infrastructure was developed with the design and application of bioclimatic architecture techniques and the use of solar energy. For the proposal model, the Sketchup software was used and the results obtained showed us the potential of Quichas for the use of its landscape, biological and environmental resources in productive activities and tourism, as well as for the development of research in sustainable agriculture, considering the dynamics that characterize its systematic geography.
\end{abstract}

Index Terms-Bioclimatic architecture, biodiversity, center for ecological research, restoration, sustainable development.

\section{INTRODUCTION}

The Quichas town has numerous of natural, ecological and ecosystem resources due to its location in a high Andean area near two important mountain ranges (mountain range Huayhuash and mountain range Raura), however, they are not being used properly to allow sustainable use of it and therefore it presents absence of specific investigations of the zone; to help counteract their environmental and biological problems for the conservation of these potential resources.

Some of these problems are: pollution of water by mining, glacial retreat, illegal mining, overgrazing, intensive agriculture, shortage in tourism development, among others. A territory that does not have specific studies where they provide solutions for remediation, conservation or studies where we can discover the benefits provided by this area, is at

Manuscript received October 9, 2019; revised January 6, 2020.

Doris Esenarro, Leslie Anco is with the Faculty of Geographical, Environmental and Ecotourism Engineering, Federico Villarreal National University, Lima 1, Peru (e-mail: desenarro@unfv.edu.pe, 2015237572@unfv.edu.pe).

Ivana Escate was with Faculty of Geographical, Environmental and Ecotourism Engineering, Federico Villarreal National University, Lima 1 Peru (e-mail: 2015233705@unfv.edu.pe).

Carla Tassara is with the Faculty of School of Architecture and Urbanism, Federico Villarreal National University, Lima 1, Peru (e-mail: 2019316991@unfv.edu.pe).

Ciro Rodriguez is with the Faculty of Computer and Electronic Engineering, Federico Villarreal National University, Lima 1, Peru (e-mail: crodriguez@unfv.edu.pe). risk of being threatened with great speed and will therefore be predated and devastated.

The Ecological Research Center is a public research center created with the purpose of promoting basic and applied research in terrestrial ecology. Its objective is to generate new knowledge and develop innovative tools in the field of terrestrial ecology, as well as providing valuable information for decision-making and for the improvement of the environmental planning and management systems of the territory.

The project will be able to investigate and improve the ecosystems, environment and the ecotourism activity in the town of Quichas. Opportunities to scientific students of our country will be given. Moreover, the students of the Quichas town can participate in research or collaborate in them for their academic strengthening. The building will provide an attractive opportunity for tourists as a bird watching point.

The architectural design of the ecological research center adapts to the needs of national community of research to solve social, economic and ecological aspects. The project considers environmental issues such as thermal comfort, constructive materials that helps to conserve the environment [1], use of natural resources of energy [2], [3], use of clean technologies and the reuse of rainwater by collectors.

In this investigation, special sustainable equipment had to be designed and thus taking advantage of the natural space, making a true touristic site for a great ecological, architectural and social use.

\section{METHOD}

\section{A. Sample}

The temporal scope of the investigation was during the month of April and the information collected in the field to be used was the month July of this year, which covers a period of 4 months. The space area of the province of Oyon belongs to the department of Lima; which had a study sample in the heart of Quichas, located on the left bank of the Quichas River in the Oyon Sub-basin, about 500 meters above sea level.

\section{1) Geographical location and survey taking}

The research area is politically located in the district of Oyon, in the province of Oyon, department of Lima. Hydrographically it belongs to the hydrographic basin of Huaura - Oyon, within the western slope of the Andes. Geographically it is located in the adjoining area to the Raura Mountain Range and the location of the areas visited and / or 
surveyed is specified in the following figure:

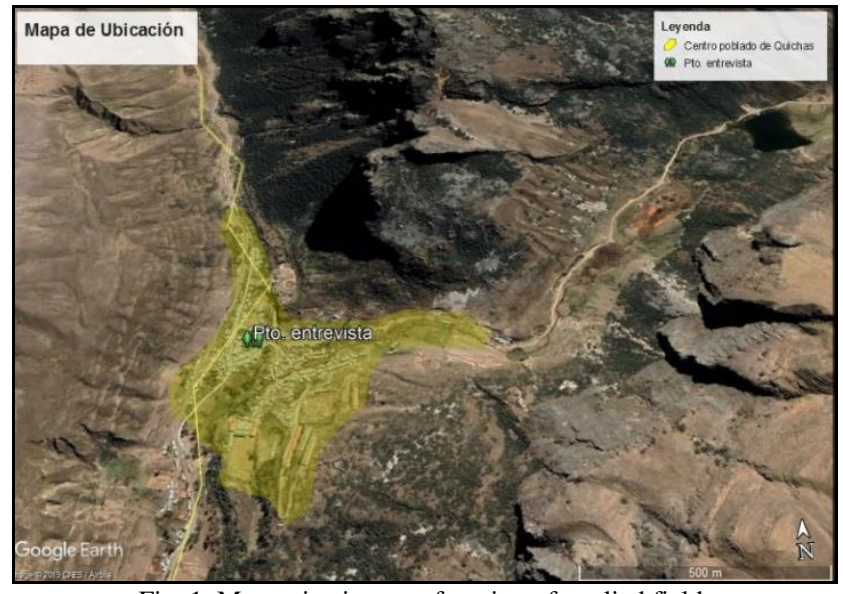

Fig. 1. Magnetization as a function of applied field.

\section{B. Research Design}

\section{1) Type of investigation}

Trans sectional: Since the evaluation was carried out in a certain period of time.

\section{2) Level of investigation}

Descriptive: the territory and the situation are described through the study in the circumstance of a given time and space.

\section{Materials}

The following are the materials used for this investigation:

\section{1) Cartographic information}

The base cartographic information has been taken from the national charts in the 1:100000 scale. They have been obtained from the National Geographic Institute (IGN), as well as Google Earth satellite images (QuickBird images).

TABLE I: CARTOGRAPHIC MATERIALS

\begin{tabular}{cc}
\hline Material & Description \\
\hline $\begin{array}{c}\text { National Maps and } \\
\text { Images }\end{array}$ & Escale: $1: 100000$ \\
& Pages: 22-j (Oyon Sheet) and 21-j (Yanahuanca \\
& Sheet) \\
& Google Earth Images Year: 2019 \\
\hline
\end{tabular}

\section{2) Thematic maps}

- Map of snow-covered mountains, lakes and lagoons

- Map of tourist attractions and archeological sites

- Accessibility Map

D. Software

- SKETCHUP 2016: It is a program of graphic design and modeling in three dimensions based on faces. It is used for the modeling of urban planning, architecture, civil engineering, industrial design, scenic design, GIS, videogames or movies environments

- ArcGis: Software it was used for georeferenced of the research site.

- Google Earth Pro: it was used to make a morphological survey of the research site.

\section{RESEARCH STAGES}

Preliminary stage: It consists of the bibliographic review and compilation of the information used in the preparation of the proposal for the Ecological Research Center in the town of Quichas. In this stage, we proceeded with a study of the area with the purpose that in the field stage the taking of points and information gathering is with the appropriate spatial perspective.

\section{A. The Data Collection Techniques Were}

- Development of thematic maps of the area or area of influence.

- Use of the technique of interpretation of satellite images using physiographic method up to the landscape elements level.

- Study and reading of thesis, documents or articles related to our project or of similar objective.

- Bibliographic review and records of the study area.

Field stage: We proceeded with the gathering of information, application of interviews, photographs and the determination of areas of direct and indirect influence. As well as verification of the tourist attractions, deficiencies of the infrastructure of the town, health system, educational system, and the ecological environmental situation presented at that time. All the environmental and anthropogenic impacts that generate the depredation of biodiversity and the needs of the population were also identified [4].

Cabinet Stage: With all the information obtained by the field visit and information from the area, a bioclimatic and sustainable infrastructure [5], [6] for the study area was proposed through:

- Bioclimatic architectural techniques

- Needs of the population shown through the interviews.

- Time address for passive solar energy use.

- Use of architectural software for modeling.

- Ecological and ecotourism principles for its elaboration.

\section{Current Diagnosis}

The town of Quichas has a perimeter of $2.36 \mathrm{~km}$ and an area of $0.19 \mathrm{~km} 2$, of which it represents $0.022 \%$ of the entire district of Oyon (with $874 \mathrm{~km} 2$ of surface). It extends from 395 masl at outfall of the Quichas River, to 5250 masl maximum point located in its Huaura Glacier, its average height being 3250 masl.

They have a sanitation system from places near the town, except the communities of Quichas that are further away.

They also have an electricity system that is supplied by the mining company Raura, with more than 60 years of functionality

The economic activities which the population of the town of Quichas carry out every day for economical support of their families are the following:

- Farming

- Cattle raising

- Mining

- Fish farming: Which was first encouraged by the school in Quichas is increasing, but it's showing pollution problems.

In this sector, the town of Quichas, does not have a good development and management of tourism activity, much less 
ecotourism. There is no infrastructure for the development of tourism, but with great potential since they have several attractions around them. They obtain as payment 3.00 soles per car that enters Quichas, half of the fee is for the municipality that gives it to senior citizens and the other half for the employee. This was stablished 5 years ago.

\section{PROPOSAL}

\section{A. Purpose}

Our purpose is to collaborate to the new generation of scientific contributions of environmental, ecological, social, economic and ecotourism solutions in the area, achieving the recovery and revaluation of existing and threatened biodiversity [7]. Moreover, the improvement of the quality of life of the population of Quichas through trained job opportunities, creation of ecotourism products and services.

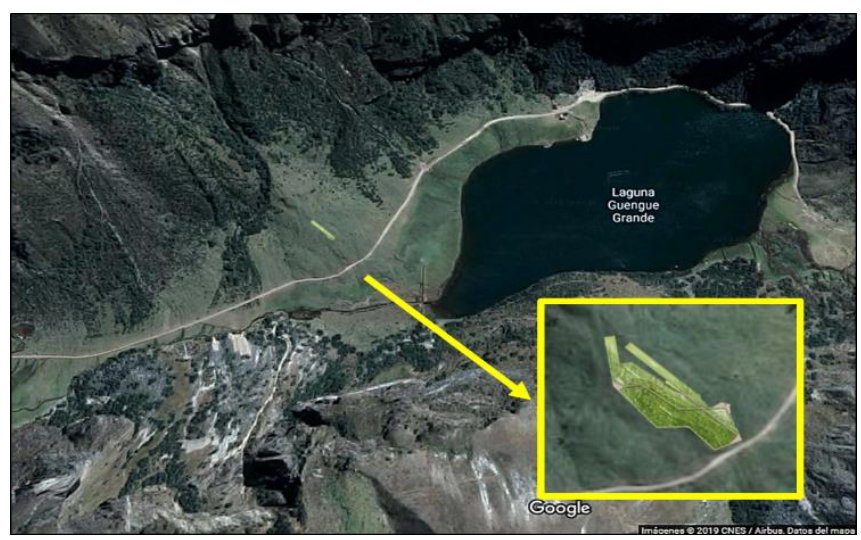

Fig. 2. Location of the sustainable bioclimatic infrastructure project.

\section{B. Infrastructure Description}

Distinguished by being a narrow strip with a lot of topographic slope towards the street. This is an opportunity to improve and build this front, containing the geography through a building excavated on the hillside, resulting in a construction of apparently lower height, and positioning the main front to the north that benefits the sunning of the project and indoor environmental comfort.

It presents the highest part of the topography with stunning views towards the Guengue Grande Lagoon and abundant native vegetation. It was decided to intervene in a respectful way the environment, putting in value the natural area and panoramic views through overlapping paths in the exposed area that guide to a secondary access to the research center, some meeting points and outside contemplation. The roofs of the building will be the extension of the vegetation cover, merging landscape and construction.

The Ecological Research Center consists of two main areas that will receive different use, linked by an opening space that relate and serve as a common program to both. This space is transformed into the essence of the proposal, place of social and scientific exchange, place of great thermal comfort and thermal regulation, place of crossing between private and public. It is defined as a place of permanence type greenhouse, open to the public and sheltered from the climate of high Andean area as Quichas, where cultural activities, scientific tourism and scientific research are generated.

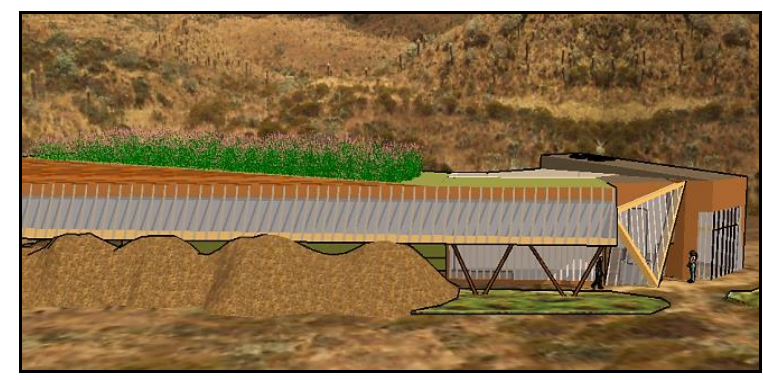

Fig. 3. A narrow strip with a lot of topographic slope towards the street.

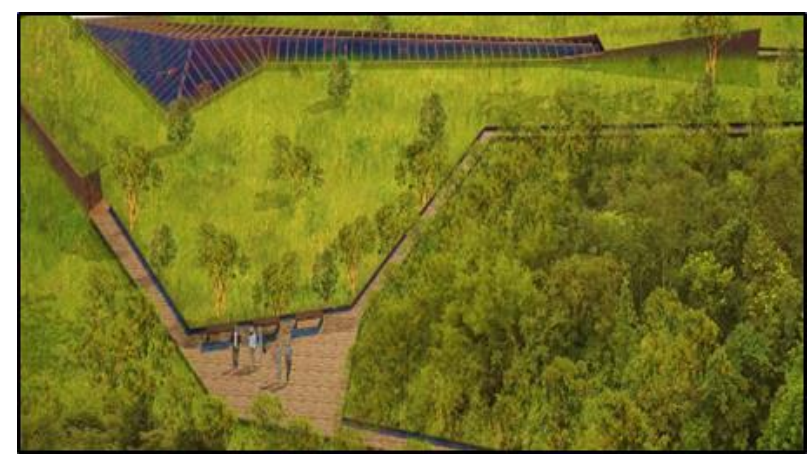

Fig. 4. The center covers will be the extension of the green areas.

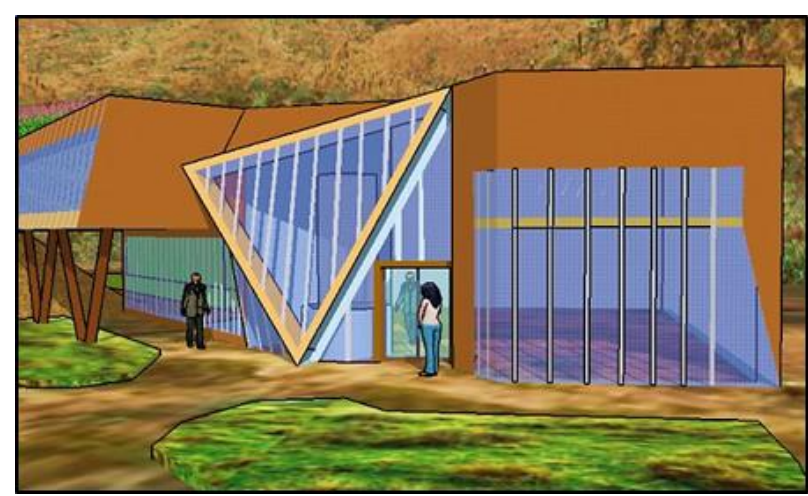

Fig. 5. Place of great thermal comfort and thermal regulation, place of mixing between private and public.

\section{Proposed Clean Technologies}

- Solar panels (a)

- Solar Lighting - Passive Solar Energy

- Solar collectors

- Solar Posts, Solar Sunflower

- Greenhouse Area

\section{Sustainable Finishes}

- Vegetable cover (b)

- Clay bricks (c)

- Use of Stipa Ichu plants

- Hygrothermal Floor

- Acoustic comfort - Glass ceilings and wooden columns

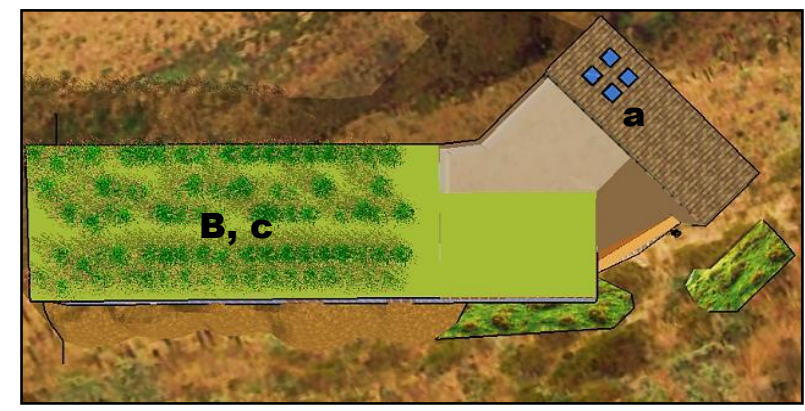

Fig. 6. Technology identification and sustainable finishes. 


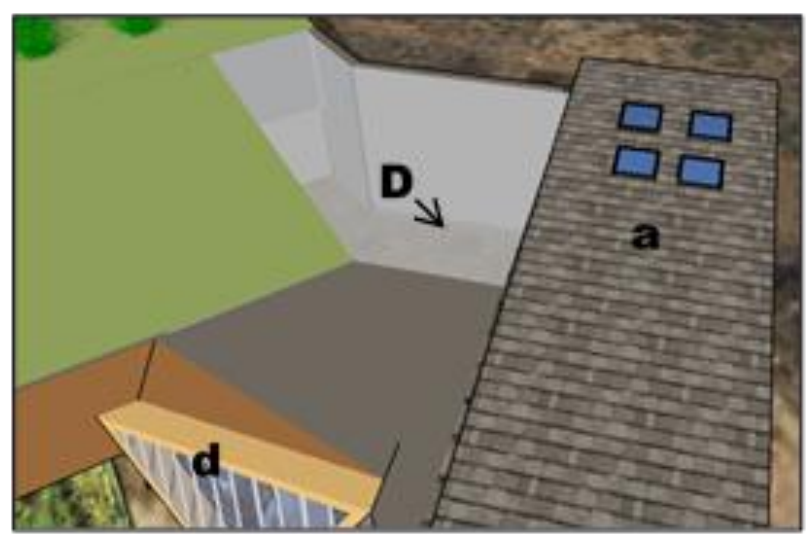

Fig. 7. Solar panels and acoustic comfort.

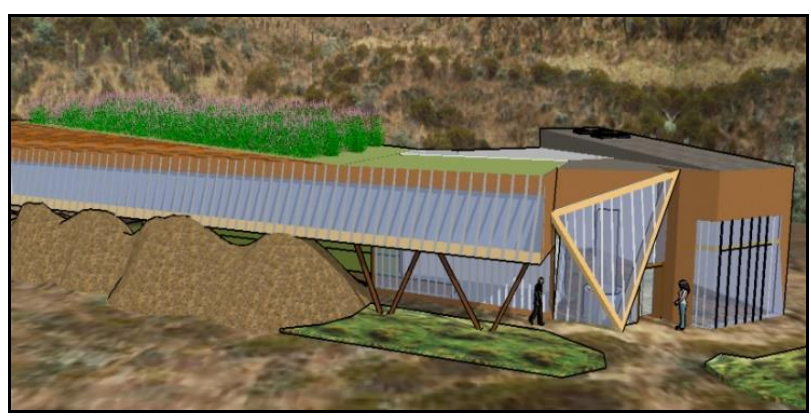

Fig. 8. Panoramic view of the proposal.

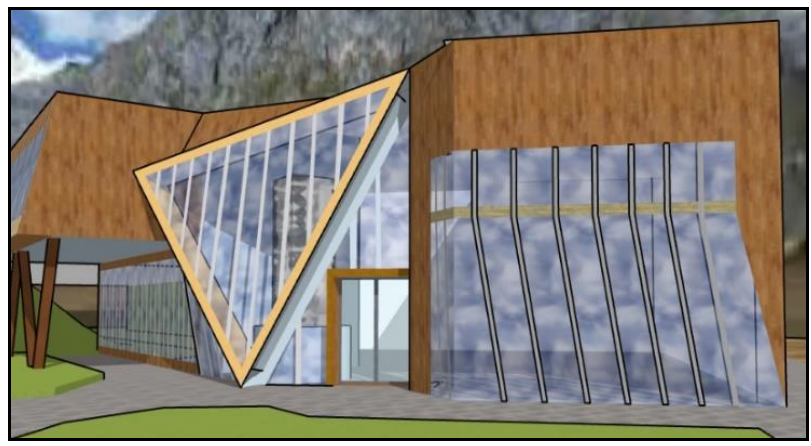

Fig. 9. View of the entrance of the research Center.

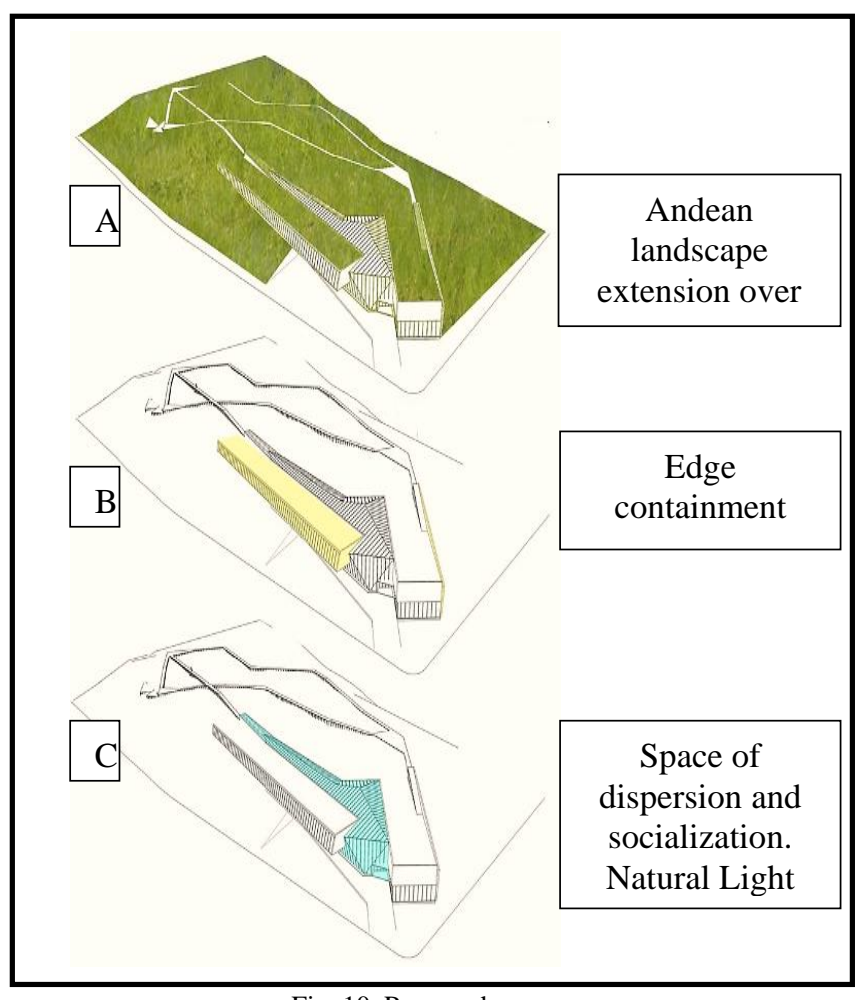

Fig. 10. Proposed spaces.

\section{Conclusions}

\section{A. General Conclusion}

The town of Quichas has a potential landscape, biological and environmental resources to be exploited in productive research activities. It constitutes a potential and beneficial scenario for the implementation of a sustainable bioclimatic infrastructure such as the Ecological Research Center that allows us to restore and revalue the benefits of this area in a vision of sustainable development.

\section{B. Specific Conclusions}

1) The general diagnosis of the town of Quichas has allowed to determine the variability and affectation of the Natural resources, the potential of research and ecotourism that possess the evaluated area. According to the results, the town represents $0.022 \%$ of the entire district of Oyon, which is not even $1 \%$ of the District territory, however it has great primary resources for the regulation of the ecological system of the area and the stability of local and nearby populations. With the application of the territorial planning criteria, it is expected to organize the priorities of Quichas' town for its development and the radical elimination of activities that generate negative impacts and an excessive degradation of biodiversity [8].

2) The proposal of a sustainable bioclimatic infrastructure used in the research center of ecological approach is adapted to the landscape without altering the communities of fauna, flora or components of the environment (water, soil and air). Furthermore, knowing the needs of the population of Quichas as well as the needs of the country in terms of research in rural areas.

3) This project will generate an economic opportunity for the people of the town with ecotourism activities an alternative solution to avoid mining work.

\section{RECOMMENDATIONS}

1) Interdisciplinary work must be carried out between various entities and professionals. The climatic variety must be one of the indicators to formulate the bioclimatic norm that is necessary for each region. National Building Regulations do not contemplate energy efficiency or environmental protection. There is poor legislation or regulations about this topic.

2) It is recommended to carry out further research regarding this proposal by civil engineers and specialized architects to generate better contributions that strengthen the proposal.

3) Field verification is necessary since bibliographic information is not always true as to the time space that was published, and the situations of each territory change over time, due to fortuitous or occasional events. Therefore, a mandatory field evaluation is recommended to strengthen the proposals of any project to be carried out.

\section{CONFLICT OF INTERESTS}

This research was carried out as a contribution to the knowledge, society and academic purposes in a 
multidisciplinary environment, "The authors declare that we have no conflicts of interest".

\section{AUTHOR CONTRIBUTIONS}

A carried out the research design; $\mathrm{AB}$ analyzed the data; $\mathrm{AC}$ carried out the design of the $\mathrm{ABC}$ and D study area. We carried out the exploratory field study, the authors' contribution is reflected in all the research approved in its final version.

\section{REFERENCES}

[1] S. Shams, K. Mahmud, and M. Al-Amin, "A comparative analysis of building materials for sustainable construction with emphasis on $\mathrm{CO}_{2}$ reduction," International Journal of Environment and Sustainable Development, Department of Civil and Environmental Engineering, Islamic University of Technology (IUT), 2011, vol. 10, no. 4, pp. 364-374

[2] EPEC, The Renewable Energies, 2016

[3] R. Manton et al., "Energy efficiency in Norwegian households Identifying motivators and barriers with a focus group approach," International Journal of Environment and Sustainable Development, 2014, vol. 13, no. 1, pp. 3-19, Ireland, 2013.

[4] F. Kahn et al., Contribution to the High Andean Flora of the Oyón District, Lima, Peru, Peruvian Biology Magazine, 2016.

[5] A. S. Danjaji and M. Ariffin, "Green infrastructure policy for sustainable urban development," International Journal of Environment and Sustainable Development, 2017, vol. 16, no. 2, pp. 112-127, 2017.

[6] J. R. Aguilar, "A review of acoustic design criteria for school infrastructure in Chile," Journal Construction Engineering, vol. 34, no. 2,2018 .

[7] J. Sierra et al., Biodiversity, An Alert, Mexico, 2010

[8] S. S. Alica, "Protection of nature and biological diversity in Turkey. International article," International Journal of Environment and Sustainable Development, 2014, vol. 13, no. 3, pp. 316-337, Turkey.

Copyright $\odot 2020$ by the authors. This is an open access article distributed under the Creative Commons Attribution License which permits unrestricted use, distribution, and reproduction in any medium, provided the original work is properly cited (CC BY 4.0).

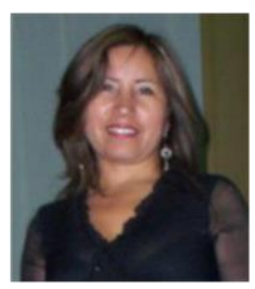

Doris Esenarro is System Engineer. She got the bachelor of architecture of the National University Federico Villarreal, Lima, Peru. She is professor of Faculty of Environmental Engineering of the University Federico Villarreal, professor of the Graduate School EUPG. Contribution: Proposal of clean technologies for the project.

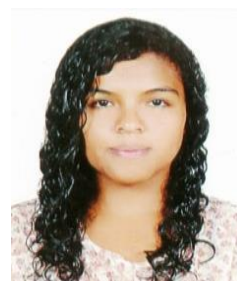

Ivana Escate is student at the Faculty of Ecotourism Engineering of the National University Federico Villarreal. Contributions: Development of the proposal of the project.

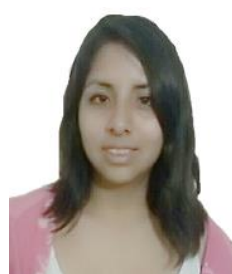

Leslie Anco is student at the Faculty of Ecotourism, Engineering of the National University Federico Villarreal. Contributions: Development of the proposal of the project.

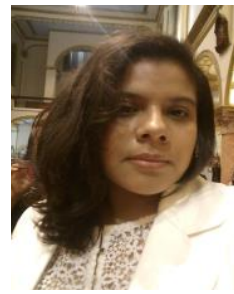

Carla Tassara is master's student in environmenta management and she got the bachelor in architecture and urbanism at the National University Federico Villarreal. Contributions: Development of the proposal of the project.

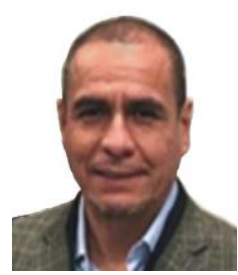

Ciro Rodriguez is industrial engineer of the National University Federico Villarreal, Lima, Peru 1990. He has worked in the National Registry of Identification and Civil Status RENIEC, since 2003 is associate professor of the Faculty of Computer and Electronic Engineering of the University Federico Villarreal, professor of the Graduate School EUPG and the School of Software Engineering of the Nationa University Mayor de San Marcos. Contributions: Evaluation of the social, environmental and economic viability of the project. 